\title{
PENGARUH SUHU EKSTRAKSI TERHADAP AKTIVITAS ANTIOKSIDAN EKSTRAK METANOLIK Eucheuma spinosum
}

\author{
Putu Tara Hradaya Komala ${ }^{1}$, Amir Husni ${ }^{2 \star}$ \\ ${ }^{1}$ Departemen Perikanan Fakultas Pertanian Universitas Gadjah Mada \\ ${ }^{2}$ Pusat Kajian Ketahanan dan Keberlanjutan Hasil Laut Departemen Perikanan Fakultas Pertanian \\ Universitas Gadjah Mada
}

Diterima: 18 Januari 2021/Disetujui: 22 Februari 2021

^Korespondensi: a-husni@ugm.ac.id

Cara sitasi: Komala PTH, Husni A. 2021. Pengaruh suhu ekstraksi terhadap aktivitas antioksidan ekstrak metanolik Eucheuma spinosum. Jurnal Pengolahan Hasil Perikanan Indonesia. 24(1): 1-10.

\begin{abstract}
Abstrak
Eucheuma spinosum merupakan alga merah yang banyak dibudidayakan dan termasuk salah satu komoditas unggulan karena memiliki senyawa fenolik dan flavonoid yang mampu berperan sebagai antioksidan. Senyawa fenolik dan flavonoid pada E. spinosum dapat diperoleh melalui proses maserasi menggunakan metanol yang pada umumnya dilakukan pada suhu ruang. Proses ekstraksi untuk mendapatkan hasil maksimum dapat dipercepat dengan cara meningkatkan suhu ekstraksi. Penelitian ini bertujuan untuk menentukan aktivitas antioksidan E. spinosum yang diekstraksi menggunakan metanol dengan suhu 55, 65, dan $75^{\circ} \mathrm{C}$. Sebelum diekstraksi rumput laut dicuci bersih dan dikeringkan pada oven bersuhu $40{ }^{\circ} \mathrm{C}$ selama 24 jam. Ekstraksi dilakukan dengan metanol 80\% (1:10, b/v). Parameter yang diuji pada penelitian ini yaitu rendemen, uji fitokimia, total fenolik, total flavonoid, dan aktivitas antioksidan meliputi uji DPPH dan FRAP. Data penelitian mengindikasikan bahwa suhu ekstraksi memengaruhi total fenolik maupun aktivitas antioksidan baik hasil uji DPPH maupun FRAP, namun tidak berpengaruh terhadap rendemen dan total flavonoid. Suhu ekstraksi $55^{\circ} \mathrm{C}$ menghasilkan ekstrak dengan daya antioksidan paling tinggi $\left(\mathrm{IC}_{50} \mathrm{DPPH}\right.$

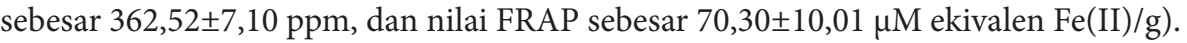

Kata kunci: DPPH, FRAP, rumput laut merah, total fenolik, total flavonoid

\section{Extraction Temperature Affect on Methanolic Extract Antioxidant Activity of Eucheuma spinosum}

\begin{abstract}
A red alga Eucheuma spinosum is widely cultivated and also one of the superior commodities because it has phenolic and flavonoid compounds that can act as antioxidants. Phenolic content and flavonoids in E. spinosum can be obtained through a maceration process with methanol as a solvent which is generally carried out at room temperature. The extraction process to obtain maximum yield can be accelerated by increasing the extraction temperature. This research aims to determine the antioxidant activity of E. spinosum extracted using methanol at temperatures of 55,65 , and $75^{\circ} \mathrm{C}$. Before extraction, the seaweed was washed and dried in an oven at $40{ }^{\circ} \mathrm{C}$ for 24 hours. Extraction was carried out with $80 \%$ methanol in a ratio of 1:10 (w/v). The parameters analyzed in this research were yield, phytochemical test, total phenolic content (TPC), total flavonoids, antioxidant activity including DPPH and FRAP. The data indicated that the extraction temperature affected total phenolic and antioxidant activity of both DPPH and FRAP, but did not affect the yield and total flavonoids. Extraction temperature of $55^{\circ} \mathrm{C}$ resulted extract with higher antioxidant activity with an $\mathrm{IC}_{50} \mathrm{DPPH}$ value was $362.52 \pm 7.10 \mathrm{ppm}$ and FRAP value $70.3010 .01 \mu \mathrm{M}$ equivalent to $\mathrm{Fe}$ (II)/g.
\end{abstract}

Keyword: DPPH, FRAP, red seaweed, total flavonoids, total phenolic content 


\section{PENDAHULUAN}

Rumput laut adalah salah satu sumber daya hayati yang banyak tumbuh di perairan Indonesia. Fathmawati et al. (2014) menyatakan bahwa sekitar 60-70\% kebutuhan pasar dunia akan rumput laut dipasok dari Indonesia. Rumput laut merah seperti Eucheuma spinosum umumnya tumbuh di perairan yang banyak tersebar hampir di seluruh perairan Indonesia (Santoso dan Nugraha 2008). Manfaat rumput laut antara lain dapat digunakan sebagai sumber antioksidan (Sari et al. 2015; Dolorosa et al. 2017; Nurjanah et al. 2017). Selain sebagai penghasil karagenan, E. spinosum juga merupakan salah satu komoditas unggulan karena memiliki senyawa fenolik yang mampu berperan sebagai antioksidan (Hanapi et al. 2013).

Senyawa fenolik yang ada pada E. spinosum dapat diperoleh melalui proses ekstraksi dengan pelarut metanol (Podungge et al. 2018). Altemimi et al. (2017) menyatakan bahwa metanol merupakan pelarut polar yang memiliki efektivitas yang tinggi dan juga merupakan salah satu pelarut yang ekonomis. Proses ekstraksi E. spinosum dapat dilakukan dengan cara maserasi. Metode maserasi memiliki kekurangan utama yakni waktu ekstraksi yang diperlukan sangat lama (Maleta et al. 2018). Menurut Demsi et al. (2019) proses ekstraksi untuk mendapatkan hasil maksimum dapat dipercepat dengan cara meningkatkan suhu ekstraksi. Hal ini diperkuat oleh Soehendro et al. (2015) yang melaporkan bahwa peningkatan suhu ekstraksi $\left(45\right.$ ke $\left.75^{\circ} \mathrm{C}\right)$ mampu meningkatkan aktivitas antioksidan $(68,08 \pm 1,29$ ke $80,90 \pm 0,86)$. Menurut Husainah (2020) suhu ekstraksi sebaiknya tidak jauh berbeda dengan titik didih pelarut. Berdasarkan hal tersebut maka pada penelitian ini digunakan variasi suhu 55 , 65 , dan tertinggi yakni $75^{\circ} \mathrm{C}$.

Beberapa penelitian mengenai aktivitas antioksidan pada variasi suhu ekstraksi telah dilakukan sebelumnya di antaranya pada ekstraksi biji melinjo (Soehendro et al. 2015), empulur batang sagu baruk Arenga microcarpha B. (Landjang et al. 2017), dan jahe merah Zingiber officinale var. Rubrum (Ibrahim et al. 2015). Penelitian mengenai variasi suhu ekstraksi terhadap aktivitas antioksidan ekstrak metanol E. spinosum belum dilakukan. Penelitian ini bertujuan untuk menentukan aktivitas antioksidan E. spinosum yang diekstraksi menggunakan metanol dengan suhu 55,65 , dan $75^{\circ} \mathrm{C}$.

\section{BAHAN DAN METODE Bahan dan Alat}

Bahan utama yang dipakai pada penelitian ini antara lain rumput laut E. spinosum basah, metanol (Merck, AS), etanol (Merck, AS), reagen follin ciocalteau, kuersetin, $\mathrm{AlCl}, 2,2$-diphenyl-1picrylhydrazyl (DPPH) (Merck, AS), dan 2,4,6-tris(2-pyridyl)-s-triazine (TPTZ) (Sigma-Aldrich, Jerman). Peralatan yang digunakan antara lain oven (Drying Oven 68-DYO200, Esco, Singapura), blender (Miyako BL101PL, Miyako, Indonesia), miller (Fomac FCT-Z300, PT Toko Mesin Toksindo, Indonesia), vorteks (Barnstead Thermolyne Tipe 37600 MixEr, AS), centrifuge (Tipe H-26F Kokusan Corporation, Jepang), hot plate stirrer (F20500011 Velp AREC Heating Stirrer, Italia), dan spektrofotometer UV-Vis (Perkinlemer Lambda 25, AS).

\section{Preparasi sampel}

Sampel E. spinosum diambil dari Desa Batumulapan, Kecamatan Nusa Penida, Kabupaten Klungkung, Provinsi Bali pada bulan Januari 2020. Sampel diambil pada pukul 10.00 WITA di kedalaman $20 \mathrm{~cm}$ dari surut terendah. Sampel yang telah diambil kemudian dimasukkan ke dalam plastik gelap dan stirofoam yang telah diberi es batu untuk selanjutnya dibawa ke laboratorium. Sampai di laboratorium, sampel dibilas memakai air tawar sampai bersih, lalu dimasukkan ke dalam freezer selanjutnya dikeringkan. Preparasi sampel kering berpedoman pada penelitian yang dilaksanakan oleh Ling et al. (2015). Rumput laut segar dicuci dengan air tawar kemudian pelekap (holdfast) dan epifit yang terlihat dihilangkan. Sampel segar kemudian dikeringkan memakai oven (suhu $40{ }^{\circ} \mathrm{C}, 24$ jam) sehingga didapatkan sampel rumput laut kering. Rumput laut kering selanjutnya digiling memakai blender dan miller kemudian diayak memakai ayakan 40 mesh untuk mendapatkan ukuran yang 
seragam. Sampel dalam bentuk bubuk ditempatkan dalam wadah kedap udara dan ditempatkan dalam freezer hingga dilakukan analisis lebih lanjut.

\section{Ekstraksi E. spinosum}

Ekstraksi E. spinosum dilakukan mengacu Ling et al. (2015) dengan beberapa modifikasi. Bubuk E. spinosum sebanyak $5 \mathrm{~g}$ ditambah $50 \mathrm{~mL}$ metanol $80 \%(1: 10, \mathrm{w} / \mathrm{v})$. Sampel dimaserasi selama 3 jam dengan perlakuan suhu yakni 55,65 , dan $75{ }^{\circ} \mathrm{C}$ pada hot plate stirrer dengan kecepatan $200 \mathrm{rpm}$. Campuran kemudian disentrifugasi pada $1400 \mathrm{rpm}$ selama 20 menit. Supernatan yang dihasilkan didekantasi ke dalam botol dan residu diekstraksi kembali. Supernatan digabungkan dan selanjutnya digunakan untuk perhitungan rendemen, uji fitokimia, total fenolik, total flavonoid, dan uji daya antioksidan.

\section{Perhitungan rendemen}

Rendemen diperoleh dengan cara melakukan perbandingan berat ekstrak E. spinosum yang dihasilkan dengan berat bubuk rumput laut sebelum ekstraksi yang digunakan. Perhitungan rendemen mengacu pada Kurniawati et al. (2016) dengan rumus:

Rendemen $=\frac{\text { Berat ekstrak }}{\text { Berat kering }} \times 100 \%$

\section{Analisis total fenolik}

Analisis total fenolik mengacu pada metode yang digunakan oleh Ahmad et al. (2015) dengan beberapa modifikasi. Langkah uji yang dilakukan adalah sebagai berikut: 1) Pereaksi $\mathrm{Na}_{2} \mathrm{CO}_{3} \quad 7 \%$ dibuat dengan menimbang 3,5 $\mathrm{g} \mathrm{Na}_{2} \mathrm{CO}_{3}$, lalu dilarutkan memakai aquabides sampai mencapai volume $50 \mathrm{~mL}$. 2) Larutan standar asam galat disiapkan dengan cara menimbang $10 \mathrm{mg}$ asam galat kemudian dilarutkan memakai metanol sampai mencapai volume $10 \mathrm{~mL}$ sampai mencapai volume $25 \mathrm{~mL}$ dan diperoleh larutan dengan kadar 100 ppm. Selanjutnya larutan tersebut diambil sebanyak 0,$2 ; 0,4 ; 0,6 ; 0,8$, dan $1 \mathrm{~mL}$, selanjutnya diberi metanol sampai volume mencapai $10 \mathrm{~mL}$ sehingga didapatkan larutan masing-masing dengan konsentrasi 2, 4, 6, 8, dan $10 \mathrm{ppm}$. 3) Larutan standar asam galat ditera dengan cara masing-masing konsentrasi tersebut ditambah reagen Folin-Ciocalteau sebanyak $0,4 \mathrm{~mL}$, kemudian dikocok lalu didiamkan 4-8 menit. Setelah didiamkan, berikutnya ditambah $0,4 \mathrm{~mL} \mathrm{Na}_{2} \mathrm{CO}_{3} 7 \%$, lalu dikocok sampai homogen. Selanjutnya dilakukan penambahan aquabides sampai volume mencapai $10 \mathrm{~mL}$ dan ditempatkan pada suhu ruang selama 30 menit, lalu diukur absorbansi pada panjang gelombang $744,8 \mathrm{~nm}$. Kurva kalibrasi dibuat dengan cara membuat korelasi antara absorbansi dan konsentrasi asam galat $(\mu \mathrm{g} / \mathrm{mL})$.

Pengukuran total fenolik ekstrak E. spinosum dilakukan dengan cara larutan ekstrak diambil sebanyak $0,1 \mathrm{~mL}$ lalu ditambah reagen Folin-Ciocalteau sebanyak $0,4 \mathrm{~mL}$, kemudian dikocok lalu didiamkan 4-8 menit. Berikutnya ditambah $0,4 \mathrm{~mL} \mathrm{Na} 2 \mathrm{CO}_{3} 7 \%$, lalu dikocok hingga homogen. Selanjutnya aquabides ditambahkan hingga volume mencapai $10 \mathrm{~mL}$ lalu dibiarkan pada suhu ruang selama 30 menit. Langkah berikutnya dilakukan pengukuran serapan pada panjang gelombang $74,8 \mathrm{~nm}$. Kadar total fenolik yang terkandung dalam ekstrak dinyatakan dalam ekuivalen asam galat (Galic Acid Equivalent). Perhitungan total fenolik mengacu metode Wan-Ibrahim et al. (2010) dengan rumus:

Total fenolik GAE $=\left(\frac{\mathrm{mg}}{\mathrm{g}} \mathrm{GAE}\right)=\mathrm{c} .\left(\frac{\mathrm{v}}{\mathrm{m}}\right)$

Keterangan:

c: kadar total fenolik dari kurva standar (mg/L)

$\mathrm{v}$ : banyaknya ekstrak yang digunakan (L) $\mathrm{m}$ : berat ekstrak (g)

\section{Analisis total flavonoid}

Pengujian total flavonoid merujuk pada metode yang digunakan oleh Ahmad et al. (2015) dengan sedikit modifikasi yakni: 1) Larutan standar kuersetin dibuat dengan menimbang $10 \mathrm{mg}$ kuersetin, kemudian diencerkan menggunakan $10 \mathrm{~mL}$ metanol sehingga menghasilkan larutan 1.000 ppm. Larutan tersebut diambil sebanyak $1 \mathrm{~mL}$ lalu diencerkan menggunakan $10 \mathrm{~mL}$ metanol sehingga menjadi larutan 100 ppm. Dari larutan $100 \mathrm{ppm}$ selanjutnya dibuat seri konsentrasi yakni 10, 20, 30, 40, 50 ppm. Larutan standar tersebut selanjutnya ditambah metanol sebanyak $3 \mathrm{~mL}$, kalium asetat $1 \mathrm{M}$ 
sebanyak $0,2 \mathrm{~mL}, \mathrm{AlCl}_{3} 10 \%$ sebanyak 0,2 $\mathrm{mL}$, lalu diberi aquabides hingga volume menjadi $10 \mathrm{~mL}$. Selanjutnya disimpan pada suhu ruang dengan waktu 30 menit. Serapan dimonitor memakai spektrofotometer UV-Vis menggunakan panjang gelombang $431 \mathrm{~nm}$.

Pengukuran total flavonoid dilakukan dengan cara larutan ekstrak diambil sebanyak $0,1 \mathrm{~mL}$ kemudian ditambah metanol sebanyak $3 \mathrm{~mL}$, kalium asetat sebanyak $0,2 \mathrm{~mL}, \mathrm{AlCl}_{3}$ $10 \%$ sebanyak $0,2 \mathrm{~mL}$, dan ditambahkan aquabides hingga volume menjadi $10 \mathrm{~mL}$. Selanjutnya larutan disimpan pada ruang kedap cahaya selama 30 menit. Absorbansi diukur menggunakan spektrofotometer UVVis pada jarak gelombang $431 \mathrm{~nm}$. Kadar flavonoid sampel dinyatakan dalam bentuk ekuivalen kuersetin (Quercetin Equivalent). Perhitungan total flavonoid mengacu pada metode Syafitri et al. (2014) dengan rumus:

Total flavonoid QE $=$ c. $\left(\frac{\mathrm{v}}{\mathrm{m}}\right)$

Keterangan:

c: kadar flavonoid dari kurva standar (mg/L)

$\mathrm{v}$ : isi ekstrak (L)

$\mathrm{m}$ : berat ekstrak (g)

\section{Penapisan fitokimia}

Analisis fitokimia dilaksanakan dalam rangka menyelidiki zat metabolit sekunder yang ada pada rumput laut E. spinosum. Pengujian senyawa fitokimia merujuk pada studi yang dilakukan oleh Sangi et al. (2008) dengan beberapa modifikasi, meliputi uji steroid, triterpenoid, dan tanin. Uji steroid dan triterpenoid dilaksanakan dengan langkah sebagai berikut: 1) Sampel yang telah diekstraksi diambil sebanyak $2 \mathrm{~mL}$ lalu diberi $3 \mathrm{~mL}$ asam asetat anhidrat, kemudian didiamkan dalam waktu 15 menit. 2) Sebanyak enam tetes larutan tersebut diteteskan ke dalam tabung reaksi lalu diberi 2-3 tetes asam sulfat pekat. Keberadaan senyawa steroid diindikasikan dengan terbentuknya warna biru, sedang senyawa triterpenoid diindikasikan dengan adanya warna merah jingga atau ungu. Langkah-langkah uji tanin yaitu: 1) Sebanyak $2 \mathrm{~mL}$ sampel yang telah diekstraksi diambil kemudian diberi etanol sampai ekstrak terendam. 2) Selanjutnya sebanyak $1 \mathrm{~mL}$ larutan dimasukkan ke dalam tabung reaksi lalu diberi $\mathrm{FeCl}_{3} 1 \%$ sebanyak 2-3 tetes. Adanya senyawa tanin diindikasikan adanya warna hitam kebiruan atau hijau.

\section{Aktivitas Antioksidan Metode Radical Scavenging Activity (RSA) DPPH}

Analisis aksi antioksidan menggunakan metode DPPH mengacu pada Virsa et al. (2014). Larutan DPPH dengan konsentrasi $50 \mathrm{ppm}$ disiapkan dengan menimbang 5 mg DPPH lalu dilarutkan menggunakan metanol sebanyak $100 \mathrm{~mL}$ dalam labu takar. Selanjutnya dibuat larutan sampel $1.000 \mathrm{ppm}$ dan seri konsentrasi yakni 10, 50, 100, 150, dan $200 \mathrm{ppm}$. Larutan stok standar $100 \mathrm{ppm}$ disiapkan dengan menimbang $1 \mathrm{mg}$ kuersetin lalu diencerkan menggunakan metanol sampai volume $10 \mathrm{~mL}$. Seri konsentrasi larutan yang dibuat yakni 5, 10, 15, 20, dan 25 ppm.

Pengukuran aksi antioksidan blangko dilaksanakan dengan cara mengambil larutan DPPH sebanyak $4 \mathrm{~mL}$, di-vortex lalu disimpan pada tempat gelap dengan suhu $37{ }^{\circ} \mathrm{C}$. Pengukuran absorbansi dilakukan memakai panjang gelombang $517 \mathrm{~nm}$. Pengukuran aksi antioksidan ekstrak E. spinosum dilaksanakan melalui cara larutan sampel dari masingmasing konsentrasi diambil sebanyak $0,5 \mathrm{~mL}$, lalu diberi 3,5 mL DPPH. Larutan di-vortex dan disimpan dalam ruang gelap dengan suhu $37^{\circ} \mathrm{C}$. Absorbansi ditera menggunakan panjang gelombang $517 \mathrm{~nm}$. Penentuan aksi antioksidan larutan standar dilaksanakan dengan mengambil kuersetin sebanyak $0,5 \mathrm{~mL}$ untuk masing-masing konsentrasi. Kemudian diberi 3,5 mL larutan DPPH. Larutan di-vortex, kemudian disimpan pada ruangan gelap dengan suhu $37^{\circ} \mathrm{C}$. Absorbansi ditera memakai panjang gelombang 517 nm. Perhitungan aksi penghambatan (\%) dilakukan memakai rumus:

$\%$ penghambatan $=\frac{\text { Absorbansi blanko-Absorbansi sampel }}{\text { Absorbansiblanko }} \times 100 \%$

Selanjutnya dilakukan perhitungan $\mathrm{IC}_{50}$ dengan mengacu pada Dewi et al. (2018). Besarnya $\mathrm{IC}_{50}$ dihitung dengan membuat kurva hubungan antara konsentrasi sampel dan $\%$ penghambatan antioksidan. 


\section{Aktivitas Antioksidan dengan Metode Ferric Reducing Antioxidant Power (FRAP)}

Analisis antioksidan dengan metode FRAP dalam penelitian ini merujuk pada penelitian Selawa et al. (2013) melalui tahapan sebagai berikut: 1) Disiapkan larutan bufer asetat dengan $\mathrm{pH}$ 3,6 dengan cara menimbang natrium asetat trihidrat $\left(\mathrm{CH}_{3} \mathrm{COONa} .3 \mathrm{H}_{2} \mathrm{O}\right)$ sebanyak $0,775 \mathrm{~g}$ lalu ditambahkan $4 \mathrm{~mL}$ asam asetat pekat kemudian diencerkan memakai akuades dalam labu takar sampai volume mencapai $250 \mathrm{~mL}$. 2) Pembuatan larutan 2,4,6-tripiridil-s-triazina (TPTZ) dengan konsentrasi $10 \mathrm{mmol} / \mathrm{mL}$ dilakukan dengan cara $0,15 \mathrm{~g}$ TPTZ diencerkan dalam $40 \mathrm{mmol} / \mathrm{L} \mathrm{HCl}$ sampai volume mencapai $50 \mathrm{~mL}$. Larutan $40 \mathrm{mmol} / \mathrm{L} \mathrm{HCl}$ disiapkan dengan cara mengencerkan $\mathrm{HCl}$ pekat sebanyak $0,828 \mathrm{~mL}$ dalam akuades sebanyak $250 \mathrm{~mL}$. 3) Pembuatan larutan $20 \mathrm{mmol} / \mathrm{L}$ $\mathrm{FeCl}_{3} \cdot 6 \mathrm{H}_{2} \mathrm{O}$ dengan cara $\mathrm{FeCl}_{3} \cdot 6 \mathrm{H}_{2} \mathrm{O}$ ditimbang dengan jumlah $0,54 \mathrm{~g}$ kemudian dilarutkan menggunakan akuades dalam labu takar sampai volume mencapai $100 \mathrm{~mL}$. 4) Pembuatan reagen FRAP dilakukan dengan cara mencampurkan bufer asetat sebanyak 25 $\mathrm{mL}$, larutan $\mathrm{FeCl}_{3} \cdot 6 \mathrm{H}_{2} \mathrm{O}$ sebanyak 2,5 mL, dan larutan TPTZ sebanyak 2,5 mL dalam labu takar kemudian diberi akuades sampai volume mencapai $100 \mathrm{~mL}$. 5) Pembuatan larutan larutan stock $\mathrm{FeSO}_{4} \cdot 7 \mathrm{H}_{2} \mathrm{O}$ dengan konsentrasi $10.000 \mu \mathrm{mol} / \mathrm{L}$, dilakukan dengan cara 2,78 gram $\mathrm{FeSO}_{4} .7 \mathrm{H}_{2} \mathrm{O}$ dilarutkan menggunakan $1.000 \mathrm{~mL}$ akuades. Kemudian diambil 100 $\mathrm{mL}$ larutan stock $\mathrm{FeSO}_{4} \cdot 7 \mathrm{H}_{2} \mathrm{O}$ konsentrasi $10.000 \mu \mathrm{mol} / \mathrm{L}$ lalu diencerkan sampai 1.000 $\mathrm{mL}$ untuk mendapat $\mathrm{FeSO}_{4} \cdot 7 \mathrm{H}_{2} \mathrm{O}$ dengan konsentrasi $1.000 \mu \mathrm{mol} / \mathrm{L}$. Selanjutnya larutan $\mathrm{FeSO}_{4} \cdot 7 \mathrm{H}_{2} \mathrm{O}$ dengan konsentrasi $1.000 \mu \mathrm{mol} / \mathrm{L}$ diambil masing-masing sebanyak 0,$1 ; 0,2 ; 0,3$; 0,4 ; dan $0,5 \mathrm{~mL}$ lalu dimasukkan ke dalam labu ukur berbeda lalu ditambah akuades $100 \mathrm{~mL}$, sehingga terbentuk larutan standar $\mathrm{FeSO}_{4} \cdot 7 \mathrm{H}_{2} \mathrm{O}$ dengan konsentrasi berturutturut $1,2,3,4$, dan $5 \mu \mathrm{mol} / \mathrm{L}$. 5) Peneraan panjang gelombang maksimum didapat dari peneraan serapan dari standar $\mathrm{FeSO}_{4} \cdot 7 \mathrm{H}_{2} \mathrm{O}$ pada konsentrasi paling besar $(1.000 \mu \mathrm{mol} / \mathrm{L})$. Larutan standar tersebut selanjutnya diambil 1 mLlalu diberi reagen FRAP sebanyak $3 \mathrm{~mL}$ dan ditera pada setiap panjang gelombang antara 588-598 nm memakai spektrofotometer UVVis. 6) Absorbansi sampel diukur dengan cara larutan ekstrak E. spinosum diambil $0,1 \mathrm{~mL}$ lalu diberi $3 \mathrm{~mL}$ reagen FRAP dan dimasukkan ke dalam tabung reaksi. Berikutnya larutan diukur serapannya memakai spektrofotometer menggunakan panjang gelombang $596 \mathrm{~nm}$.

\section{Analisis Data}

Analisis data penelitian dilaksanakan menggunakan IBM SPSS versi 19. Langkah pertama yang dilakukan yakni uji normalitas menggunakan Kolmogorov-Smirnov. Selanjutnya dilaksanakan uji homogenitas memakai Levene's test. Data penelitian dapat dikatakan berdistribusi normal dan homogen dengan syarat $p>0,05$. Setelah mengetahui bentuk distribusi data, selanjutnya dilakukan uji beda nyata antar data. Uji data parametrik menggunakan uji Duncan, dan uji data nonparametrik memakai Kruskal-Wallis. Apabila pada uji Kruskal-Wallis terdapat beda nyata antar data maka diteruskan dengan uji Mann Whitney.

\section{HASIL DAN PEMBAHASAN Rendemen, Total Fenolik, dan Total Flavonoid}

Data pengaruh suhu ekstraksi pada rendemen, total fenolik, dan total flavonoid dapat dilihat pada Table 1. Rendemen ekstrak E. spinosum yang diekstraksi dengan metanol $80 \%$ pada suhu 55,65 , dan $75^{\circ} \mathrm{C}$ berturut-turut yakni $3,46 \pm 0,39 ; 3,29 \pm 0,14 \%$; dan $2,94 \pm 0,02 \%$. Hasil analisis menunjukkan bahwa suhu ekstraksi tidak memengaruhi $(p>0,05)$ rendemen ekstrak. Rendemen E. spinosum yang diekstraksi menggunakan variasi suhu jauh berbeda dengan rendemen E. spinosum yang diekstraksi pada suhu ruang selama 24 jam (12,44\%) yang dilakukan Sari et al. (2015). Menurut Kawiji et al. (2015) suhu ekstraksi yang tinggi mampu mempercepat proses reaksi tetapi hal ini juga dapat mengakibatkan sebagian pelarut menguap, dengan demikian jumlah pelarut menjadi berkurang dan tidak cukup untuk mengekstrak bahan.

Total fenolik ekstrak metanol E. spinosum yang diekstraksi dengan suhu berbeda dapat dilihat pada Table 1. Total fenolik ekstrak 
Table 1Effect of extraction temperature on yield, total phenol, and total flavonoids of E. spinosum total methanolic extract

\begin{tabular}{lcrr}
\hline $\begin{array}{c}\text { Extraction } \\
\text { temperature }\end{array}$ & Yield (\%) & $\begin{array}{c}\text { Total phenolic } \\
(\mathrm{mg} \text { GAE/g extract) }\end{array}$ & $\begin{array}{c}\text { Total flavonoids } \\
(\mathrm{mg} \text { QE/g extract) }\end{array}$ \\
\hline $55^{\circ} \mathrm{C}$ & $3.46 \pm 0.39^{\mathrm{a}}$ & $170.02 \pm 15.37^{\mathrm{a}}$ & $789.21 \pm 17.25^{\mathrm{a}}$ \\
$65^{\circ} \mathrm{C}$ & $3.29 \pm 0.14^{\mathrm{a}}$ & $158.30 \pm 17.16^{\mathrm{a}}$ & $587.43 \pm 10.63^{\mathrm{a}}$ \\
$75^{\circ} \mathrm{C}$ & $2.94 \pm 0.02^{\mathrm{a}}$ & $95.71 \pm 8.35^{\mathrm{b}}$ & $403.50 \pm 49.09^{\mathrm{a}}$ \\
\hline
\end{tabular}

Note: ${ }^{a}$ same letter in the same column indicate no significant difference $(p>0.05)$

E. spinosum yang diekstrak dengan suhu 55, 65, dan $75{ }^{\circ} \mathrm{C}$ adalah $170,02 \pm 15,37$; $158,30 \pm 17,16$; dan $95,71 \pm 8,35 \mathrm{mg}$ GAE/g. Perbedaan suhu ekstraksi berpengaruh nyata pada total fenolik $(p<0,05)$. Total fenolik ekstrak E. spinosum yang diekstraksi pada suhu 55 dan $65^{\circ} \mathrm{C}$ berbeda nyata dengan $75^{\circ} \mathrm{C}$. Total fenolik ekstrak E. spinosum mengalami penurunan yang signifikan pada suhu $75^{\circ} \mathrm{C}$. Hal ini dapat disebabkan karena fenol dapat mengalami kerusakan struktur akibat suhu ekstraksi yang tinggi (Hwang dan Thi 2014). Fenolik merupakan senyawa termosensitif sehingga memungkinkan terjadinya hidrolisis dan pengurangan kadar fenol pada suhu tinggi (Wenjuan et al. 2010). Faktor lain yang dapat memengaruhi kandungan total fenolik yakni waktu ekstraksi. Sari et al. (2013) menyatakan bahwa waktu ekstraksi juga dapat memengaruhi kadar fenolik karena waktu ekstraksi yang terlalu lama dapat meningkatkan peluang adanya reaksi oksidasi senyawa fenolik akibat paparan oksigen yang semakin lama dapat menurunkan jumlah total fenolik terekstrak.

Data pengaruh suhu ekstraksi terhadap kadar total flavonoid ekstrak E. spinosum terdapat pada Table 1. Kadar total flavonoid ekstrak E. spinosum yang diekstrak dengan suhu 55, 65, dan $75{ }^{\circ} \mathrm{C}$ masing-masing adalah $789,21 \pm 17,25 ; \quad 587,43 \pm 10,63 ;$ dan $403,50 \pm 49,09 \mathrm{mg}$ QE/g. Total flavonoid mengalami penurunan dengan meningkatnya suhu esktraksi yang digunakan. Akan tetapi perubahan tersebut tidak menunjukkan pengaruh secara nyata pada total flavonoid $(p>0,05)$. Total flavonoid pada suatu ekstrak dapat semakin menurun kadarnya seiring dengan meningkatnya suhu ekstraksi, hal ini dapat terjadi karena flavonoid mudah rusak pada suhu tinggi (Sảadah et al. 2017).
Turunnya total senyawa flavonoid seiring dengan meningkatnya suhu juga bisa terjadi karena suhu tinggi dapat merusak struktur sel bahan sehingga komponen yang ada mudah bermigrasi dan menjadi mudah rusak oleh bermacam reaksi kimia yang mengikutkan cahaya maupun oksigen (Zainol et al. 2009).

\section{Penapisan Fitokimia}

Berdasarkan hasil penapisan fitokimia ekstrak E. spinosum yang diekstraksi menggunakan suhu berbeda menunjukkan bahwa E. spinosum mengandung senyawa triterpenoid, namun tidak terdeteksi adanya steroid dan tanin. Hasil positif adanya senyawa triterpenoid ditunjukkan dengan terbentuknya warna jingga. Terbentuknya warna jingga terjadi karena triterpenoid mampu membentuk warna apabila direaksikan dengan $\mathrm{H}_{2} \mathrm{SO}_{4}$ pekat (Yanuarti etal. 2017). Hasil penapisan fitokimia E. spinosum bersesuaian dengan hasil penelitian yang dilaksanakan Sari et al. (2015). Jenis triterpenoid yang terdapat pada E. spinosum adalah golongan triterpenoid asam karboksilat (Ahmad dan Nasrum 2013).

\section{Aktivitas Antioksidan RSA DPPH}

Pengaruh suhu ekstraksi E. spinosum terhadap aktivitas antioksidan DPPH $\left(\mathrm{IC}_{50}\right)$ terdapat pada Table 2. Aktivitas antioksidan $\mathrm{DPPH}$ yang dinyatakan dalam $\mathrm{IC}_{50}$ untuk ekstrak E. spinosum yang diekstraksi dengan suhu 55, 65, dan $75{ }^{\circ} \mathrm{C}$ secara berturutturut adalah $362,52 \pm 7,10 ; \quad 417,77 \pm 18,72$; dan 437,03 $\pm 35,03 \mathrm{ppm}$. Hasil analisis data menunjukkan perbedaan suhu ekstraksi berpengaruh secara signifikan terhadap aktivitas antioksidan ekstrak E. spinosum suhu $55^{\circ} \mathrm{C}$ dan suhu $75^{\circ} \mathrm{C}(p<0,05)$. 
Table 2 Effect of extraction temperature on antioxidant acitivity (DPPH \& FRAP) of E. spinosum methanolic extract

\begin{tabular}{lrr}
\hline \multirow{2}{*}{$\begin{array}{c}\text { Extraction } \\
\text { temperature }\end{array}$} & \multicolumn{2}{c}{ Antioxidant activity } \\
\cline { 2 - 3 } & $\mathrm{DPPH}\left(\mathrm{IC}_{50}, \mathrm{ppm}\right)$ & $\mathrm{FRAP}(\mu \mathrm{M} / \mathrm{g})$ \\
\hline $55^{\circ} \mathrm{C}$ & $362.52 \pm 07.10^{\mathrm{b}}$ & $70.30 \pm 10.01^{\mathrm{b}}$ \\
$65^{\circ} \mathrm{C}$ & $417.77 \pm 18.72^{\mathrm{bc}}$ & $78.44 \pm 03.66^{\mathrm{bc}}$ \\
$75^{\circ} \mathrm{C}$ & $437.03 \pm 35.03^{\mathrm{c}}$ & $95.04 \pm 13.62^{\mathrm{c}}$ \\
Quercetin & $14.77 \pm 00.42^{\mathrm{a}}$ & $51.90 \pm 01.83^{\mathrm{a}}$ \\
\hline Note: ${ }^{\mathrm{a}}$ same letter in the same column indicate no significant difference $(p>0.05)$
\end{tabular}

Berdasarkan nilai $\mathrm{IC}_{50}$, E. spinosum yang diekstrak pada suhu $55{ }^{\circ} \mathrm{C}$ lebih kecil dibanding suhu $75{ }^{\circ} \mathrm{C}$. Hasil tersebut menunjukkan peningkatan suhu ekstraksi dari $55{ }^{\circ} \mathrm{C}$ menjadi $75{ }^{\circ} \mathrm{C}$ menyebabkan penurunan aktivitas antioksidan (Dewi et al. 2018). Perubahan nilai $\mathrm{IC}_{50}$ ini dapat disebabkan karena berkurangnya senyawa yang dapat berperan sebagai antioksidan karena pengaruh suhu tinggi. Menurut Hwang dan Thi (2014), penggunaan ekstraksi dengan suhu yang terlalu tinggi dapat berpengaruh pada kerusakan senyawa bioaktif seperti senyawa fenolik sehingga dapat menurunkan aktivitas penghambatan radikal bebas.

Aktivitas antioksidan DPPH E. spinosum yang diekstrak dengan suhu $55^{\circ} \mathrm{C}$ lebih tinggi dibanding dengan E. spinosum yang dimaserasi oleh Sari et al. (2015) memakai etanol 70 \% dengan waktu 24 jam pada suhu ruang $\left(\mathrm{IC}_{50}\right.$ $472,14 \mathrm{ppm}$ ). Dengan demikian peningkatan suhu ekstraksi hingga $55^{\circ} \mathrm{C}$ memiliki aktivitas antioksidan yang lebih tinggi daripada ekstraksi pada suhu ruang. Penurunan aktivitas antioksidan ini berbanding lurus dengan penurunan total fenolik. Lalu lanjut menurut Soehendro et al. (2015), ekstraksi dengan suhu tinggi dapat meningkatkan kelarutan fenol akibat rusaknya struktur sel bahan. Hal ini mungkin yang menyebabkan ekstrak E. spinosum dengan suhu tinggi mempunyai aktivitas antioksidan yang lebih besar. Menurut Sari et al. (2013) peningkatan kadar fenol dapat terjadi hingga mencapai suhu tertentu namun ketika suhu optimum sudah tercapai maka dapat menyebabkan penurunan kadar total fenolik yang disebabkan oleh terdekomposisinya senyawa fenolik oleh suhu yang terlau tinggi. Pada penelitian ini suhu optimum untuk ekstraksi E. spinosum adalah
$55{ }^{\circ} \mathrm{C}$ karena aktivitas antioksidannya lebih besar apabila dibandingkan dengan ekstrak E. spinosum suhu $75^{\circ} \mathrm{C}$.

\section{Aktivitas Antioksidan Metode FRAP}

Pengaruh suhu ekstraksi E. spinosum terhadap nilai FRAP terdapat pada Table 2. Nilai FRAP E. spinosum yang diekstraksi pada suhu 55,65 , dan $75^{\circ} \mathrm{C}$ secara berturutturut yakni $70,30 \pm 10,01 ; 78,44 \pm 3,66$; dan $95,04 \pm 13,62 \mu \mathrm{M}$ ekuivalen $\mathrm{Fe}(\mathrm{II}) / \mathrm{g}$. Analisis statistik mengindikasikan bahwa adanya perbedaan suhu ekstraksi berpengaruh yang nyata terhadap nilai FRAP $(p<0,05)$. Nilai FRAP E. spinosum yang diekstraksi dengan suhu $55{ }^{\circ} \mathrm{C}$ lebih kecil dan mempunyai perbedaan yang nyata $(p<0,05)$ apabila dibandingkan dengan suhu $75{ }^{\circ} \mathrm{C}$. Hal ini menandakan kemampuan mereduksi pada ekstrak E. spinosum yang diekstraksi dengan suhu $55{ }^{\circ} \mathrm{C}$ lebih tinggi jika dibandingkan dengan ekstrak suhu $75^{\circ} \mathrm{C}$.

Nilai FRAP ekstrak E. spinosum cenderung bertambah bersamaan dengan semakin tinggirnya suhu ekstraksi. Hal ini mengindikasikan semakin tinggi suhu ekstraksi yang dipakai maka kemampuan ekstrak untuk mereduksi $\mathrm{Fe}^{3+}$ menjadi $\mathrm{Fe}^{2+}$ semakin berkurang. Metode FRAP adalah salah satu metode penentuan kandungan antioksidan secara spektrofotometri yang berdasarkan pada reduksi analog ferroin, kompleks $\mathrm{Fe}^{3+}$ dari tripiridiltriazin $\mathrm{Fe}(\mathrm{TPTZ})^{3+}$ menjadi kompleks $\mathrm{Fe}^{2+}, \mathrm{Fe}(\mathrm{TPTZ})^{2+}$ yang berwarna biru intensif oleh antioksidan pada suasana asam (Yefrida et al. 2015). Menurut Neoh et al. (2016) kemampuan mereduksi dari rumput laut sebagian besar berkaitan dengan kandungan fenoliknya. Hal ini seiring dengan data total fenolik (Table 1) cenderung 
menurun dengan meningkatnya suhu ekstraksi sehingga kemampuan mereduksi juga menurun seiring dengan bertambahnya suhu ekstraksi. Ekstrak E. spinosum yang diekstrak dengan berbagai suhu yang berbeda memiliki aktivitas antioksidan DPPH cenderung sama jika dibandingkan dengan metode FRAP. Kecenderungan seperti ini juga terjadi pada dua spesies rumput laut merah, Amansia multifida dan Meristiella echinocarpa, dari pantai Timur laut Brazil (De-Alencar et al. 2014).

Hasil FRAP standar kuersetin memiliki nilai lebih kecil jika dibandingkan dengan nilai FRAP ekstrak E. spinosum pada suhu $55{ }^{\circ} \mathrm{C}$, hal ini menandakan kemampuan mereduksi dari kuersetin lebih tinggi jika dibandingkan dengan ekstrak E. spinosum pada suhu $55^{\circ} \mathrm{C}$. Kuersetin merupakan salah satu jenis antioksidan alami dan banyak ditemukan pada hampir setiap jenis tanaman yang mempunyai aktivitas antioksidan yang sangat kuat sehingga kemampuannya untuk mereduksi juga tinggi (Jusuf 2010)

\section{KESIMPULAN}

Aktivitas antioksidan ekstrak E. spinosum menurun seiring dengan meningkatnya suhu ekstraksi. Suhu ekstraksi $55{ }^{\circ} \mathrm{C}$ mempunyai aktivitas antioksidan yang lebih besar apabila dikomparasikan dengan suhu $65^{\circ} \mathrm{C}$ dan $75^{\circ} \mathrm{C}$. Antioksidan ekstrak E. spinosum berbanding lurus dengan hasil total fenolik.

\section{UCAPAN TERIMA KASIH}

Penulis menyampaikan terima kasih kepada Fakultas Pertanian Universitas Gadjah Mada. Penelitian ini telah didanai melului skema Hibah Penelitian Kolaborasi Dosen dan Mahasiswa Fakultas Pertanian UGM tahun 2020 dengan nomor kontrak 1508/PN/ $\mathrm{PT} / 2020$.

\section{DAFTAR PUSTAKA}

Ahmad AR, Juwita, Ratulangi SAD, Malik A. 2015. Penetapan kadar fenolik dan flavonoid total ekstrak metanol buah dan daun patikala (Etlingera elatior (Jack) R.M.SM). Pharmaceutical Sciences and Research. 2(1): 1-10.

Ahmad A, Nasrum M. 2013. Inhibitive enhancement of isoniasid treatment on Mycobacterium tuberculosis through triterpenoid carbocylic acid from red algae Eucheuma spinosum. International Journal of Pharma and Bio Sciences. 4(2): B231-B237.

Altemimi A, Lakhssassi N, Baharlouei A, Watson DG, Lightfoot DA. 2017. Phytochemicals: extraction, isolation, and identification of bioactive compounds from plant extracts. Plants. 6 (42): 1-23.

De-Alencar DB, Da-Silva SR, Pires-Cavalcante KMS, De-Lima RL, Pereira-Junior FN, De-Sousa MB, Viana FA, Nagano CS, Do-Nascimento KS, Cavada BS, Sampaio AH, Saker-Samaio S. 2014. Antioxidant potential and cytotoxic activity of two red seaweed species, Amansia multifida and Meristiella echinocarpa, from the coast of Northeastern Brazil. Annals of the Brazilian Academy of Sciences. 86(1): 251-263.

Demsi RP, Ruslan, Rahim EA, Ys H. 2019. Ekstraksi pektin pada kulit buah kluwih (Artocarpus camansi Blanco) pada berbagai suhu dan konsentrasi asam sitrat. Kovalen: Jurnal Riset Kimia. 5(1): 100-108.

Dewi SR, Ulya N, Argo BD. 2018. Kandungan flavonoid dan aktivitas antioksidan ekstrak Pleurotus ostreatus. Rona Teknik Pertanian. 11(1): 1-11.

Dolorosa MT, Nurjanah, Purwaningsih S, Anwar E, Hidayat T. 2017. Kandungan senyawa bioaktif bubur rumput laut Sargassum plagyophyllum dan Eucheuma cottonii sebagai bahan baku krim pencerah kulit. Jurnal Pengolahan Hasil Perikanan Indonesia. 20(3): 633-644.

Fathmawati D, Abidin MRP, Roesyadi A. 2014. Studi kinetika pembentukan karaginan dari rumput laut. Jurnal Teknik Pomits. 3(1): 27-32.

Hanapi A, Fasya AG, Mardiyah U, Miftahurrahmah. 2013. Aktivitas antioksidan dan antibakteri ekstrak metanol alga merah Eucheuma spinosum dari perairan Wongsorejo Banyuwangi. Alchemy. 2(2): 126-137.

Husainah NU. 2020. Variasi suhu dan jenis pelarut pada ekstraksi daun tembakau 
kasturi inferior sebagai senyawa antibakteri. [Skripsi]. Jember (ID): Universitas Jember.

Hwang ES, Thi ND. 2014. Effects of extraction and processing methods on antioxidant compound contents and radical scavenging activities of laver (Porphyra tenera). Preventive Nutrition and Food Science. 19(1): 40-48.

Ibrahim AM, Yuniantha, Sriherfyna FH. 2015. Pengaruh suhu dan lama waktu ekstraksi terhadap sifat kimia dan fisik pada pembuatan minuman sari jahe merah (Zingiber officinale var. rubrum) dengan kombinasi penambahan madu sebagai pemanis. Jurnal Pangan dan Agroindustri. 3(2): 530-541.

Jusuf E. 2010. Kandungan kuersetin dan pola proteomik varietas jambu batu (Psidium guajava L.) tumbuh liar di kawasan Cibinong, Bogor. Berita Biologi. 10(3): 401-415.

Kawiji, Khasanah LU, Utami R, Aryani NT. 2015. Ekstraksi maserasi oleoresin daun jeruk purut (Citrus hystrix DC): optimasi rendemen dan pengujian karakteristik mutu. Agritech. 35(2): 178-184.

Landjang EY, Momuat LI, Suryanto E. 2017. Efek pemanasan terhadap aktivitas antioksidan ekstrak empelur batang sagu baruk (Arenga microcarpha B.). Chemistry Progress. 10(1): 8-14.

Ling ALL, Yasir S, Matanjun P, Bakar MFA. 2015. Effect of different drying techniques on the phytochemical content and antioxidant activity of Kappaphycus alvarezii. Journal of Applied Phycology. 27: 1717-1723.

Maleta HS, Indrawatil R, Limantara L, Brotosudarmo THP. 2018. Ragam metode ekstraksi karotenoid dari sumber tumbuhan dalam dekade terakhir (telaah literatur). Jurnal Rekayasa Kimia dan Lingkungan. 13(1): 40-50.

Neoh YY, Matanjun P, Lee JS. 2016. Comparative study of drying methods on chemical constituents of Malaysian red seaweed. Drying Technology. 34(14): 1745-1751.

Nurjanah, Nurilmala M, Anwar E, Luthfiyana N, Hidayat, $\mathrm{T}$ 2017. Identification of bioactive compounds of seaweed Sargassum sp and E. cotonii as raw material suncreen cream. Proceedings of the Pakistan Academy of Sciences. 54(4): 311-318.

Podungge A, Damongilala LJ, Mewengkang HW. 2018. Kandungan antioksidan pada rumput laut Eucheuma spinosum yang diekstrak dengan metanol dan etanol. Jurnal Media Teknologi Hasil Perikanan. 6(1): 197-201.

Sa’adah H, Nurhasnawati H. 2017. Perbandingan pelarut etanol dan air pada pembuatan ekstrak umbi bawang tiwai (Eleutherine americana Merr) menggunakan metode maserasi. Jurnal Ilmiah Manuntung. 1(2): 149-153.

Sangi M, Runtuwene MRJ, Simbala HEI, Makang VMA. 2008. Analisis fitokimia tumbuhan obat di Kabupaten Minahasa Utara. Chemistry Progress. 1(1): 47-53.

Santoso L, Nugraha YT. 2008. Pengendalian penyakit ice-ice untuk meningkatkan produksirumput laut Indonesia. Jurnal Saintek Perikanan. 3(2): 37-43.

Sari BL, Susanti N, Sutanto. 2015. Skrining fitokimia dan aktivitas antioksidan fraksi etanol alga merah Eucheuma spinosum. Pharmaceutical Sciences and Research. 2(2): 59-67.

Selawa W, Runtuwene MRJ, Citraningtyas G. 2013. Kandungan flavonoid dan kapasitas antioksidan total ekstrak etanol daun binahong (Anredera cordifolia (Ten) Steenis.). Pharmacon. 2(1): 18-23.

Setzer WN. 2008. Non-intercalative triterpenoid inhibitors of topoisomerase II: a molecular docking study. The Open Bioactive Compounds Journal. 1: 13-17.

Soehendro AW, Manuhara GJ, Nurhartadi E. 2015. Pengaruh suhu terhadap aktivitas antioksidan dan antimikrobia ekstrak biji melinjo (Gnetum gnemon L.) dengan pelarut etanol dan air. Jurnal Teknosains Pangan. 4(4): 15-24.

Syafitri NE, Bintang M, Falah S. 2014. Kandungan fitokimia, total fenol, dan total flavonoid ekstrak buah harendong (Melastoma affine D. Don). Current Biochemistry. 1(3): 105-115.

Virsa H, Ahmad AR, Sudir M. 2014. Uji 
aktivitas antioksidan ekstrak metanol bunga dan daun patikala (Etlingera elatior (Jack) R.M.Sm) menggunakan metode DPPH. Pharmaceutical Sciences and Research. 1(2): 86-93.

Wan-Ibrahim WI, Sidik K, Kuppusamy UR. 2010. A high antioxidant level in edibleplants is associated with genotoxic properties. Food Chemistry. 122: 11391144.

Wenjuan Q, Pan Z, Ma H. 2010. Extraction modeling and activities of antioxidants from pomegranate marc. Journal of Food Engineering. 99(1): 16-23.

Yanuarti R, Nurjanah, Anwar E, Hidayat T. 2017. Profil fenolik dan aktivitas antioksidan dari ekstrak rumput laut Turbinaria conoides dan Eucheuma cottonii. Jurnal Pengolahan Hasil Perikanan Indonesia. 20(2): 230-237.

Yefrida, Ashikin N, Refilda. 2015. Validasi metoda FRAP modifikasi pada penentuan kandungan antioksidan total dalam sampel mangga dan rambutan. Jurnal Riset Kimia. 8(2): 170-175.

Zainol MKM, Abdul-Hamid A, Abu-Bakar F, Pak-Dek S. 2009. Effect of different drying methods on the degradation of selected flavonoids in Centella asiatica. International Food Research Journal. 16: 531-537. 